\title{
Herança da resistência ao enfezamento em milho
}

\author{
Flávio Trevizoli Silveira(1), José Roberto Moro(1), Herberte Pereira da Silva(2), João Ademir de Oliveira(1) \\ e Dilermando Perecin ${ }^{(1)}$
}

\begin{abstract}
(1)Universidade Estadual Paulista, Faculdade de Ciências Agrárias e Veterinárias de Jaboticabal, Rodovia Professor Paulo Donato Castellane, s/no, CEP 14870-000 Jaboticabal, SP. E-mail: flaviots@fcav.unesp.br, jrm.1953@gmail.com, herbertesilva@yahoo.com.br, jaoliv@fcav.unesp.br, perecin@fcav.unesp.br (2)Agromen Sementes Ltda., Rodovia SP 425, Km 68, CEP 14790-000 Guaíra, SP.
\end{abstract}

Resumo - Os objetivos deste trabalho foram determinar a herança da resistência ao complexo de enfezamento em milho e determinar as melhores fontes de resistência entre as linhagens estudadas. Foram realizadas as análises dialélica e médias de gerações em linhagens de milho. Para a análise dialélica, foram cruzadas 12 linhagens de milho, em dialélico parcial. Para análises de médias de gerações, foram cruzadas três linhagens resistentes e quatro suscetíveis, para a obtenção das gerações $\mathrm{F}_{1}, \mathrm{~F}_{2}, \mathrm{RCP}_{\mathrm{R}}$ e $\mathrm{RCP}_{\mathrm{S}}$. Os trabalhos foram conduzidos em Jaboticabal, SP. A incidência de enfezamento foi avaliada no estádio fenológico R3. Efeitos significativos quanto à capacidade geral de combinação e capacidade específica de combinação foram obtidos, o que indicou que, no controle do caráter enfezamentos, estão envolvidos tanto os efeitos aditivos quanto os de dominância. Análises de médias de gerações mostraram a presença de poucos genes envolvidos com o controle da resistência, com predominância de efeitos aditivos, o que permite a seleção de genótipos resistentes. As linhagens L02, L03 e L05 poderão ser utilizadas como fontes de resistência, em futuras combinações híbridas.

Termos para indexação: análise de gerações, espiroplasma, fitoplasma, herdabilidade.

\section{Inheritance of the resistance to corn stunt}

\begin{abstract}
The objectives of this work were to determine the inheritance of resistance to corn stunt and determine the best resistance sources among the studied inbred lines. Diallel analysis and generation means were made for corn inbred lines. For the diallel analysis, twelve corn-inbred lines were crossed, in a partial diallel scheme. For the analyses of generation means, three resistant inbred lines and four susceptible ones were crossed, to obtain the $\mathrm{F}_{1}, \mathrm{~F}_{2}, \mathrm{RCP}_{\mathrm{R}}$ and $\mathrm{RCP}_{\mathrm{S}}$ generations. The experiments were carried out in Jaboticabal, SP, Brazil. Corn sfunt incidence was evaluated at the phenological phase R3. Significant effects for CGC and CEC were obtained, which indicated that both additive and dominance effects were involved in corn expression of resistance to stunt. The analyses of generation means showed that few genes are involved in the resistance control, with predominant additive effects, which allows the selection of resistant genotypes. Lineages L02, L03 and L05 may be used as resistance sources in future hybrid combinations.
\end{abstract}

Index terms: generation analysis, spiroplasma, phytoplasma, heritability.

\section{Introdução}

O complexo de enfezamentos, responsável pelos enfezamentos pálido e vermelho do milho, é causado por patógenos da classe dos molicutes, cuja transmissão é realizada pela cigarrinha-do-milho (Dalbulus maidis) (Oliveira et al., 2002a).

$\mathrm{Na}$ década de 1970, quando surgiu no Brasil, o complexo de enfezamentos foi considerado de importância secundária (Costa et al., 1971). Atualmente, com o aumento das áreas cultivadas com soja, a cultura do milho tem se constituído em valiosa opção para cultivo na safrinha, o que tem favorecido o aumento da incidência dessas doenças, com perdas significativas de produtividade. Vários autores têm relatado a importância do complexo de enfezamentos e os prejuízos que causam à cultura do milho (Massola Júnior, 2001; Oliveira et al., 2002b, 2004; Silva et al., 2003). No Paraná, já se estimaram prejuízos de US\$ 16,5 milhões na safrinha (Oliveira et al., 2003).

Considerando-se a necessidade de interação entre hospedeiro suscetível, patógeno e ambiente, para a manifestação de uma doença, qualquer alteração num desses componentes leva a mudanças no patossistema como um todo. A cultura do milho no campo, durante praticamente o ano todo, alterou o comportamento de determinadas doenças e expôs a cultura a situações até 
então inexistentes, como é o caso dos enfezamentos vermelho e pálido (Massola Júnior, 2001).

A crescente importância do complexo de enfezamentos, nos cultivos tardios e de safrinha, está relacionada ao aumento da população do inseto vetor nessa época (Silva et al., 2002a). Essa situação se acentua, quando a cultura anterior também foi o milho. Nessa condição, a população do vetor é maior e, ao migrar para as culturas mais novas, em cultivo tardio, ocasiona severas epidemias dos enfezamentos (Massola Júnior, 2001), sobretudo nas regiões plantadas com híbridos suscetíveis.

Um dos principais fatores para o aumento da incidência do complexo de enfezamentos é o fato de que, no Brasil, o milho é o único hospedeiro da cigarrinha D. maidis e dos molicutes, Spiroplasma kunkelii e Phytoplasma, este último é causador do enfezamento-vermelho (Oliveira et al., 2002a).

O milho possui grande diversidade genética com relação à resistência a patógenos (Silva et al., 2001), e o uso de genótipos resistentes é a alternativa mais eficiente para o controle dos enfezamentos (Basso, 1999; Silva et al., 2002b, 2003).

Poucos trabalhos são relatados na literatura sobre a herança da resistência ao complexo de enfezamentos em milho. Em estudos realizados com germoplasma de clima temperado, observou-se que a herança da resistência é de natureza quantitativa (Márquez Sánchez, 1982) e que os efeitos genéticos aditivos são predominantes quanto à característica de resistência (Grogan \& Rosenkranz, 1968). Há evidências de que a resistência ao espiroplasma é condicionada por vários genes (Scott \& Rosenkranz, 1974). Em estudos com germoplasma de clima tropical, também foi observada predominância de efeitos aditivos (Silva et al., 2003).

As capacidades geral (CGC) e específica de combinação (CEC) têm sido avaliadas em programas de melhoramento do milho, por meio de análises dialélicas ou em "top-crosses" com testadores de base genética ampla ou estreita. As análises dialélicas permitem a identificação dos grupos heteróticos entre populações de milho, a caracterização de linhagens para a obtenção de híbridos e estudos de resistência genética a doenças, o que possibilita determinar a melhor fonte de resistência (Silva et al., 2003).

O estudo da herança genética é fundamental, também, para determinar se o caráter é qualitativo ou quantitativo e o modo de ação predominante dos genes envolvidos com a resistência. A determinação dos parâmetros genéticos que governam a resistência permite direcionar os trabalhos de introdução de resistência, em germoplasmas suscetíveis, e possibilita maiores ganhos com a seleção, nos métodos a serem empregados. O estudo do modo de herança de um caráter permite melhor direcionar e maximizar a exploração da variabilidade genética (Silva et al., 2001).

O objetivo deste trabalho foi determinar a herança genética da resistência ao complexo de enfezamentos em milho e as melhores fontes de resistência entre as linhagens estudadas.

\section{Material e Métodos}

$\mathrm{Na}$ safrinha de 2007, foram conduzidos dois experimentos, na fazenda experimental da Faculdade de Ciências Agrárias e Veterinárias da Unesp, Jaboticabal, $\mathrm{SP}$, na região Sudeste, à altitude de $585 \mathrm{~m}$ - um para estudos de capacidade de combinação e outro para estudos de médias de gerações.

Foram utilizadas 12 linhagens endogâmicas de milho, cujas reações aos enfezamentos foram avaliadas, preliminarmente, na safrinha do ano agrícola 2003/2004, em condições de campo, em que as linhagens L01, L02, L03 e L04 foram classificadas como resistentes, e as linhagens L05, L06, L07, L08, L09, L10, L11 e L12 foram classificadas como suscetíveis (Silveira et al., 2006) (Tabela 1).

Para os estudos de capacidade de combinação, foram obtidos 32 híbridos simples, em esquema de dialélico parcial, no ano agrícola de 2005/2006. Utilizou-se o delineamento experimental de blocos ao acaso, com três repetições para pais e $F_{1}$. As parcelas foram representadas por uma fileira de $5 \mathrm{~m}$ de comprimento,

Tabela 1. Linhagens de milho avaliadas quanto à resistência aos enfezamentos, suas origens e principais características.

\begin{tabular}{clcc}
\hline Linhagem & \multicolumn{1}{c}{ Código } & Origem & Enfezamentos $^{(1)}$ \\
\hline L01 & PH970 & Sin - 18-021 & Resistente \\
L02 & PH1894 & Sin - 02-017 & Resistente \\
L03 & PH1977 & Sin - 04-044 & Resistente \\
L04 & CR800486A & - & Resistente \\
L05 & PH1173-1 & Sin - 06-001 & Suscetível \\
L06 & PH2038 & Sin - 12-056 & Suscetível \\
L07 & PH2572 & CMS 14C-012 & Altamente suscetível \\
L08 & PH2650 & CMS 07-088 & Suscetível \\
L09 & PH1048 & Sin - 60-056 & Moderadamente suscetível \\
L10 & PH1580 & Sin - 57-095 & Moderadamente suscetível \\
L11 & PH1903 & Sin - 02-020 & Moderadamente suscetível \\
L12 & PH2554 & CMS 05-022 & Moderadamente suscetível \\
\hline (1) Conforme & Silveira et al. (2006).
\end{tabular}


espaçada de $0,20 \mathrm{~m}$ entre plantas e $0,80 \mathrm{~m}$ entre fileiras, com uma população de 62.500 plantas por hectare. Dentro de cada repetição, as parcelas constituídas por linhagens receberam bordaduras de linhagem, e as parcelas constituídas por híbridos receberam bordadura de híbrido.

A análise de variância foi realizada com o método de Geraldi \& Miranda Filho (1988), para cruzamentos dialélicos parciais, por meio do programa Genes versão Windows (Cruz, 2001).

Para as análises de médias gerações, foram utilizadas as linhagens L01, L02 e L03 (resistentes) e as linhagens L05, L06, L07 e L08 (suscetíveis). As gerações $F_{2}$ e os retrocruzamentos, para o parental resistente $\left(\mathrm{RCP}_{\mathrm{R}}\right)$, e parental suscetível $\left(\mathrm{RCP}_{\mathrm{S}}\right)$ foram obtidos na safrinha do ano agrícola de 2005/2006, em área irrigada. Utilizouse o delineamento experimental de blocos ao acaso com parcelas subdivididas e três repetições, tendo-se considerado como unidade experimental a média do caráter por parcela. Essas parcelas foram constituídas pelas doze combinações híbridas (L01 x L05; L01 x L06; L01 x L07; L01 x L08; L02 x L05; L02 x L06; L02 x L07; L02 x L08; L03 x L05; L03 x L06; L03 x L07; L03 x L08), e as subparcelas pelas gerações $P_{R}$, $\mathrm{P}_{\mathrm{S}}, \mathrm{F}_{1}, \mathrm{~F}_{2}, \mathrm{RCP}_{\mathrm{R}}$ e $\mathrm{RCP}_{\mathrm{S}}$, que constituíram 12 famílias. Para efeito de análise de variância, consideraram-se gerações dentro de famílias. Em cada repetição, cada parcela foi representada por uma fileira de $5 \mathrm{~m}$ de comprimento para as gerações $P_{R}, P_{S}$ e $F_{1}$; duas fileiras de $5 \mathrm{~m}$ para as gerações $\mathrm{RCP}_{\mathrm{R}}$ e $\mathrm{RCP}_{\mathrm{S}}$; e quatro fileiras de $5 \mathrm{~m}$ para as gerações $\mathrm{F}_{2}$, com cada fileira constituída por 25 plantas. As fileiras foram espaçadas de $0,80 \mathrm{~m}$, que constituíram uma população de 62.500 plantas por hectare. Para não haver efeito de bordadura entre híbridos e linhagens, as gerações $\mathrm{P}_{\mathrm{R}}$ e $\mathrm{P}_{\mathrm{S}}$ (linhagens) receberam bordadura de linhagem, e as gerações $F_{1}$, $\mathrm{RCP}_{\mathrm{R}}, \mathrm{RCP}_{\mathrm{S}}$ e $\mathrm{F}_{2}$ (híbridos) receberam bordadura de híbrido. A análise de variância foi realizada por meio do programa SAS, com uso da transformação arc sen $(\mathrm{x} / 100)^{0,5}$, para dados de percentagem. Para determinação das estimativas de variância fenotípica, genotípica e ambiental, de cada geração, dentro de cada família, foi utilizado o procedimento PROC VARCOMP, do SAS (SAS Institute, 1999), tendo-se considerado o efeito de genótipo como aleatório. As estimativas dos efeitos aditivos (â), de dominância ( $\hat{\mathrm{d}}$ ), número de genes ( $\hat{n})$, grau médio de dominância $(\hat{\mathrm{k}})$ e herdabilidade no sentido amplo $\left(\mathrm{h}_{\mathrm{a}}^{2}\right)$ foram determinadas de acordo com metodologia proposta por Cruz \& Regazzi (1997).

Com antecedência de 30 dias da semeadura dos experimentos, semearam-se, ao redor, seis linhas de bordadura com um híbrido de milho-pipoca, altamente suscetível ao complexo de enfezamentos, para garantir a fonte de inóculo. Além disso, a área para o plantio foi escolhida em razão do histórico de alta incidência de enfezamentos, confirmada pela presença de vários plantios ao redor que manifestaram os sintomas das doenças. A semeadura dos dois experimentos foi realizada em 10/3/2007.

Para a prevenção de doenças fúngicas, foi realizada a aplicação preventiva do fungicida mancozeb, na dosagem de $2,5 \mathrm{~kg} \mathrm{ha}^{-1}$. Os demais tratos culturais seguiram os recomendados para a cultura do milho.

A incidência dos enfezamentos foi obtida no estádio fenológico R3, pelo mesmo avaliador, por meio da contagem do número de plantas da parcela que apresentavam os sintomas da doença.

\section{Resultados e Discussão}

Os sintomas predominantes em ambos os experimentos foram os do enfezamento-vermelho. Em geral, plantas com enfezamento-pálido tiveram faixas esbranquiçadas na base das folhas, secamento precoce das plantas e encurtamento de internódios, enquanto plantas com enfezamento-vermelho apresentaram clorose nas margens e ápices das folhas, com aspecto avermelhado e proliferação de espigas, o que concorda com os sintomas descritos por Oliveira et al. (2002c).

No período entre a semeadura dos experimentos e a avaliação dos enfezamentos, foram observadas temperaturas entre 17,9 e $30,28^{\circ} \mathrm{C}$, umidade relativa média de $67,5 \%$, e precipitação pluvial de $214,4 \mathrm{~mm}$ distribuídos em 15 dias.

As análises de variância mostraram variação altamente significativa $(\mathrm{p} \leq 0,01)$ entre tratamentos, quanto à resistência aos enfezamentos, em ambos os experimentos (Tabelas 2 e 3). Os efeitos de capacidade geral de combinação (CGC) foram altamente significativos $(\mathrm{p} \leq 0,01)$ para os grupos 1 (linhagens resistentes) e 2 (linhagens suscetíveis), assim como os efeitos de capacidade específica de combinação (CEC) entre os grupos 1 e 2. Esses dados são indicativos de que, como fontes de variação para resistência aos enfezamentos, estão envolvidos 
tanto os efeitos genéticos aditivos, como os efeitos de dominância. Entretanto, os valores dos quadrados médios da CGC foram superiores aos da CEC, o que sugere predominância de efeitos aditivos. Assim, para a seleção da melhor fonte de resistência, deve-se dar ênfase não só ao desempenho médio da linhagem nas combinações híbridas, mas também em combinações específicas (Tabela 2).

Várias linhagens apresentaram índices negativos em CGC, o que demonstra que, na média dos cruzamentos, elas contribuíram para diminuir a incidência dos enfezamentos. Do grupo das linhagens resistentes, a que apresentou o maior efeito negativo foi a linhagem L02 (Tabela 4) que, portanto, deve ser a que teve maior freqüência de alelos de efeitos aditivos e pode favorecer a diminuição da incidência dos enfezamentos, quando cruzada com o grupo de linhagens suscetíveis. $\mathrm{Na}$ maioria de suas combinações híbridas, com

Tabela 2. Análise de variância da incidência dos enfezamentos (\%) de 12 linhagens endogâmicas de milho e 32 cruzamentos, avaliados em relação ao dialelo parcial, em Jaboticabal, SP, na safrinha do ano agrícola 2006/2007.

\begin{tabular}{lrc}
\hline Fontes de variação & GL & Quadrado médio \\
\hline Genótipos & 43 & $0,1039^{* *}$ \\
Grupos & 1 & $1,4198^{* *}$ \\
CGC Grupo 1 & 3 & $0,1101^{* *}$ \\
CGC Grupo 2 & 7 & $0,2049^{* *}$ \\
CEC 1x2 & 32 & $0,0401^{* *}$ \\
Resíduo & 86 & 0,0108 \\
\hline
\end{tabular}

**Significativo a $1 \%$ pelo teste $\mathrm{F}$.

Tabela 3. Análise de variância da incidência dos enfezamentos, em 12 famílias e 6 gerações por família, em Jaboticabal, SP, na safrinha do ano agrícola 2006/2007.

\begin{tabular}{lcc}
\hline Fontes de variação & GL & Quadrado médio \\
\hline Repetições & 2 & $0,03749^{*}$ \\
Famílias & 11 & $0,17008^{*}$ \\
Gerações (famílias) & 60 & $0,13831^{*}$ \\
Resíduo & 142 & 0,01056 \\
\hline CV $(\%)$ & & 14,97 \\
\hline
\end{tabular}

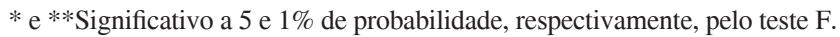

exceção da combinação com a linhagem L06, houve aumento da resistência, em que alguns cruzamentos manifestaram incidência das doenças abaixo da média dos genitores, como é o caso das combinações L02 x L05 e L02 x L07 (Tabela 5). Do grupo das linhagens suscetíveis, a L05 teve o maior efeito negativo de CGC, superior aos valores observados nas linhagens resistentes, e pode contribuir para diminuição da incidência dos enfezamentos, quando cruzada com as linhagens resistentes (Tabelas 4 e 5). Isto pode ocorrer em razão de a L05 possuir freqüência de alelos desfavoráveis muito baixa ou em caráter recessivo, que são suprimidos pela alta freqüência de alelos favoráveis das linhagens resistentes, quando em combinação. Embora a suscetibilidade seja uma característica indesejada para os programas de melhoramento do milho, em casos onde estão envolvido poucos genes a sua expressão pode ser resultante de efeitos epistáticos, que inibem a expressão de um ou mais genes que conferem a resistência. Nesses casos, o potencial da linhagem só pode ser avaliado em combinação, quando se manifestam os efeitos dos genes que controlam a resistência aos enfezamentos.

Contrariamente ao observado na linhagem L05, a linhagem L06, com o maior efeito positivo em CGC, tem contribuição negativa para a resistência (Tabela 4).

Para os programas de melhoramento, o maior interesse na seleção de genótipos, para resistência à determinada doença, é o de identificar não só o genitor que apresenta a maior freqüência de alelos favoráveis, que contribuem para a resistência, como também identificar genitores com facilidade para transmitir os genes de resistência. Alguns estudos têm demonstrado que genótipos diferentes apresentam resistência diferenciada ao complexo de enfezamentos (Silva et al., 2002b, 2003; Oliveira et al., 2005; Moro et al., 2007).

Tabela 4. Estimativas das capacidades específica e geral de combinação (CGC), obtidas dos cruzamentos entre as linhagens dos grupos 1 e 2, avaliadas quanto à incidência de enfezamentos (\%), em Jaboticabal, SP, na safrinha do ano agrícola $2006 / 2007$.

\begin{tabular}{|c|c|c|c|c|c|c|c|c|c|}
\hline \multirow[t]{2}{*}{ Grupo 1} & \multicolumn{7}{|c|}{ Grupo 2} & & \multirow[t]{2}{*}{ CGC } \\
\hline & L05 & L06 & L07 & L08 & L09 & L10 & L11 & L12 & \\
\hline \multicolumn{10}{|c|}{ Capacidade específica de combinação } \\
\hline L01 & 0,0017 & $-0,0196$ & $-0,0333$ & $-0,2152$ & $-0,0216$ & 0,0659 & 0,0739 & 0,1653 & 0,0199 \\
\hline L02 & $-0,0177$ & 0,1570 & $-0,0477$ & 0,0624 & $-0,0190$ & $-0,0325$ & 0,0595 & 0,0389 & $-0,0547$ \\
\hline L03 & 0,0280 & 0,0697 & $-0,0950$ & 0,0251 & 0,0047 & 0,1842 & 0,1512 & 0,0656 & $-0,0335$ \\
\hline L04 & $-0,1837$ & 0,1200 & 0,0503 & $-0,0286$ & 0,1390 & 0,0415 & $-0,0115$ & $-0,0781$ & 0,0683 \\
\hline CGC & $-0,1550$ & 0,1012 & $-0,0050$ & $-0,0662$ & $-0,0538$ & $-0,0113$ & 0,0957 & 0,0944 & \\
\hline
\end{tabular}


Os maiores valores em CEC negativa foram observados nos cruzamentos entre as linhagens L01 x L08 e L04 x L05. Pôde-se constatar que os cruzamentos que proporcionaram os maiores índices negativos em CEC originaram-se de genitores com alelos distintos e complementares, o que favorece a heterose e, conseqüentemente, o aumento da resistência. As médias de incidência dos enfezamentos, das combinações com os maiores efeitos negativos de CEC, ficaram abaixo da média do genitor resistente, enquanto as combinações com os maiores efeitos positivos ficaram acima da média do genitor suscetível ou com incidência muito próxima (Tabelas 4 e 5).

No experimento de médias de gerações, as combinações híbridas $\left(\mathrm{F}_{1}\right)$ com as menores médias de incidência dos enfezamentos originaram-se do cruzamento da linhagem suscetível L05 com as linhagens resistentes L02 e L03 (Tabela 6). Esses resultados confirmamosobservados, para esta linhagem, no ensaio de capacidade de combinação, e demonstram a importância, para os programas de melhoramento de milho, de estudos que expressem a contribuição efetiva de linhagens resistentes e suscetíveis para a obtenção de híbridos.
Valores negativos de heterose foram observados na maioria das combinações híbridas (Tabela 6). Valores de heterose negativa também foram encontrados em outras doenças do milho (Silva \& Moro, 2004). As combinações L02xL05, L03xL06 e L03xL08 apresentaram os menores valores de heterose, o que indica que essas linhagens possuem alelos distintos que favorecem os efeitos de dominância. Valores positivos de heterose foram observados nos cruzamentos L01 x L07, L02 x L06 e L03 x L07, o que favorece o aumento da incidência dos enfezamentos. Na maioria das famílias, foram observadas médias de incidência dos enfezamentos nas gerações $F_{2}$, superiores àquelas das $F_{1}$. Com a segregação e recombinação dos genes na $F_{2}$, os efeitos de dominância são divididos pela metade, em decorrência do surgimento dos locos em homozigose. Nessas condições, podem-se observar médias menores de incidência dos enfezamentos, nas combinações cujo genitor contribui mais favoravelmente com locos de efeitos aditivos. Nos retrocruzamentos do genitor resistente $\left(\mathrm{RCP}_{\mathrm{R}}\right)$, as médias de incidência foram inferiores às observadas nas gerações $\mathrm{F}_{2}$, contrariamente ao observado para o $\mathrm{RCP}_{\mathrm{S}}$. Isto se deve ao fato de que, nos retrocruzamentos do parental resistente, os efeitos

Tabela 5. Médias de incidência dos enfezamentos (\%), em 12 linhagens endogâmicas de milho, nos grupos 1 (L01 a L04, resistentes) e 2 (L05 a L12, suscetíveis) e seus 32 cruzamentos, obtidos em Jaboticabal, SP, na safrinha do ano agrícola $2006 / 2007$.

\begin{tabular}{|c|c|c|c|c|c|c|c|c|c|}
\hline Linhagens & L05 & L06 & L07 & L08 & L09 & L10 & L11 & L12 & Incid. na linhagem \\
\hline L01 & 26,98 & 56,84 & 40,26 & 15,29 & 35,64 & 52,83 & 70,95 & 86,82 & 23,26 \\
\hline L02 & 18,03 & 73,33 & 29,72 & 35,33 & 27,57 & 30,64 & 56,67 & 53,39 & 5,81 \\
\hline L03 & 24,22 & 62,47 & 26,94 & 33,38 & 32,52 & 62,79 & 75,00 & 60,75 & 2,77 \\
\hline L04 & 14,60 & 88,77 & 58,67 & 39,19 & 65,00 & 56,35 & 64,79 & 54,28 & 31,68 \\
\hline Incidência na linhagem & 39,74 & 79,76 & 82,22 & 64,06 & 48,35 & 49,27 & 82,59 & 89,72 & \\
\hline
\end{tabular}

Tabela 6. Médias de incidência de enfezamentos (\%), nas gerações parental resistente (PR), parental suscetível (PS), cruzamentos PRxPS $\left(\mathrm{F}_{1}\right)$, autofecundação das $\mathrm{F}_{1}\left(\mathrm{~F}_{2}\right)$, retrocruzamentos das $\mathrm{F}_{1}$ para o parental resistente (RCPR), retrocruzamentos das $\mathrm{F}_{1}$ para o parental suscetível (RCPS) e valores de heterose das 12 famílias avaliadas em Jaboticabal, SP, na safrinha do ano agrícola 2006/2007.

\begin{tabular}{|c|c|c|c|c|c|c|c|c|}
\hline \multirow[t]{2}{*}{ Combinações híbridas } & \multicolumn{7}{|c|}{ Gerações } & \multirow[t]{2}{*}{ Heterose $^{(1)}$} \\
\hline & $(\mathrm{PR} \times \mathrm{PS})$ & PR & PS & $\mathrm{F}_{1}$ & $\mathrm{~F}_{2}$ & RCPR & RCPS & \\
\hline 1 & L01 x L05 & 18,77 & 65,86 & 40,26 & 55,59 & 32,25 & 51,29 & $-2,055$ \\
\hline 2 & L01 x L06 & 26,13 & 83,16 & 49,33 & 82,99 & 45,98 & 95,33 & $-5,315$ \\
\hline 3 & L01 x L07 & 15,63 & 85,30 & 55,50 & 78,00 & 38,82 & 75,99 & 5,035 \\
\hline 4 & L01 x L08 & 23,13 & 83,66 & 36,61 & 69,37 & 39,15 & 88,96 & $-16,785$ \\
\hline 5 & L02 x L05 & 11,11 & 55,26 & 10,56 & 48,06 & 24,76 & 47,21 & $-22,625$ \\
\hline 6 & L02 x L06 & 13,59 & 97,22 & 81,58 & 81,92 & 66,18 & 98,58 & 26,175 \\
\hline 7 & L02 x L07 & 12,73 & 91,17 & 39,13 & 71,03 & 46,30 & 79,40 & $-12,820$ \\
\hline 8 & L02 x L08 & 11,19 & 82,19 & 53,31 & 60,86 & 39,15 & 83,42 & 6,620 \\
\hline 9 & L03 x L05 & 10,00 & 59,35 & 16,46 & 22,25 & 15,67 & 72,22 & $-18,215$ \\
\hline 10 & L03 x L06 & 21,66 & 100,00 & 29,00 & 87,04 & 55,60 & 98,67 & $-31,830$ \\
\hline 11 & L03 x L07 & 15,83 & 91,30 & 57,42 & 55,79 & 31,13 & 75,16 & 3,855 \\
\hline 12 & L03 x L08 & 15,83 & 77,90 & 24,03 & 37,31 & 20,02 & 56,57 & $-22,835$ \\
\hline
\end{tabular}


de dominância se somam aos efeitos aditivos dos locos que conferem resistência, contrariamente ao que ocorre com os retrocruzamentos do parental suscetível, em que os efeitos dos locos que conferem a suscetibilidade são pronunciados (Tabela 6).

Dos parentais resistentes, a linhagem L03 foi a que proporcionou as menores médias de incidência dos enfezamentos nas gerações híbridas, seguidas pelas linhagens L01 e L02 respectivamente (Tabela 6).

A utilização da análise de médias de gerações para detectar o tipo de ação gênica envolvida no controle da resistência à doenças tem sido relatada em vários trabalhos (Pinho, 1998; Schuelter et al., 2003; Silva \& Moro, 2004; Lopes et al., 2007). No presente trabalho, as análises de médias de gerações mostraram 2,2 genes no controle do caráter, o que determina herança qualitativa associada à herdabilidade de $78,47 \%$ no sentido amplo. Os efeitos aditivos foram negativos e predominantes $(-32,10)$, o que contribuiu para a diminuição da ocorrência dos enfezamentos, enquanto os efeitos de dominância foram de $1,14 \mathrm{e}$ determinaram o grau médio de dominância de $-0,04$. Predominância de efeitos genéticos aditivos também foi encontrada em outros estudos de herança da resistência aos enfezamentos (Nelson \& Scott, 1973; Grogan \& Rosenkranz, 1968; Silva et al., 2003). No presente trabalho, foram estimados dois genes envolvidos no controle da resistência ao complexo do enfezamento, contrariamente ao observado por Scott \& Rosenkranz (1974) e Márquez Sánchez (1982), que identificaram, em germoplasmas de clima temperado, controle quantitativo. Altos índices de herdabilidade para a incidência dos enfezamentos também foram encontrados por Silva et al. (2003).

Mediante a avaliação da capacidade de combinação e os estudos de herança da resistência aos enfezamentos do milho, verificou-se que a L05, classificada como suscetível quando em combinação, favoreceu $\mathrm{o}$ aumento da resistência (Tabela 4). Para os programas de melhoramento do milho, essa informação é muito importante, porque na maioria das vezes, as linhagens que se mostram suscetíveis são descartadas após a primeira avaliação de resistência.

Relatos relacionados a linhagens suscetíveis, que favorecem o aumento da resistência às doenças quando em combinação, não foram encontrados na literatura consultada. A maioria dos artigos relacionados à herança do caráter resistência a doenças tem como enfoque principal os efeitos genéticos que controlam o caráter. Trabalhos futuros devem enfocar não só os efeitos genéticos, mas, sobretudo, a contribuição efetiva - para a resistência - de linhagens resistentes e suscetíveis.

\section{Conclusões}

1. A herança genética da resistência aos enfezamentos é predominantemente de alelos de efeito aditivo, embora efeitos de dominância também estejam presentes.

2. No controle do caráter da resistência aos enfezamentos estão envolvidos poucos genes, o que caracteriza herança qualitativa.

3. Os efeitos da heterose devem ser considerados na escolha de combinações específicas que favoreçam o aumento da resistência aos enfezamentos.

4. As linhagens L02 (PH1894), L03 (PH1977) e L05 (PH1173-1) podem ser utilizadas como fonte de resistência aos enfezamentos do milho.

\section{Referências}

BASSO, M.C. Síntese de compostos de milho (Zea mays L .) com resistência ao "complexo de enfezamento". 1999. 122p. Tese (Doutorado) - Escola Superior de Agricultura Luiz de Queiroz, Piracicaba.

COSTA, A.S.; KITAJIMA, E.W.; ARRUDA, S.C. Moléstia de vírus e de micoplasma do milho em São Paulo. Revista da Sociedade Brasileira de Fitopatologia, v.4, p.39-41, 1971.

CRUZ, C.D. Programa Genes: versão Windows: aplicativo computacional em genética e estatística. Viçosa: Imprensa Universitária, 2001. 648p.

CRUZ, C.D.; REGAZZI, A.J. Modelos biométricos aplicados ao melhoramento genético. Viçosa: UFV, 1997. 390p.

GERALDI, I.O.; MIRANDA FILHO, J.B. Adapted models for the analysis of combining ability of varieties in partial diallel crosses. Revista Brasileira de Genética, v.11, p.419-430, 1988.

GROGAN, C.O.; ROSENKRANZ, E.E. Genetics of host reaction to corn stunt virus. Crop Science, v.8, p.251-254, 1968.

LOPES, M.T.G.; LOPES, R.; BRUNELLI, K.R.; SILVA, H.P.; MATIELlO, R.R.; CAMARGO, L.E.A. Controle genético da resistência à mancha-de-Phaeosphaeria em milho. Ciência Rural, v.37, p.605-611, 2007.

MÁRQUEZ SÁNCHEZ, F. The genetic improvement of resistance to the maize disease stunt and downy mildew in Nicaragua. Revista Chapingo, v.7, p.26-27, 1982.

MASSOLA JÚNIOR, N.S. Enfezamento vermelho e pálido: doenças em milho causadas por molicutes. Semina, Ciências Agrárias, v.22, p.237-243, 2001.

MORO, J.R.; SILVEIRA, F.T.; CARGNELUTTI, A.F. Dissimilaridade genética em sessenta e quatro linhagens de milho 
avaliadas para resistência ao complexo enfezamento. Revista Biologia e Ciências da Terra, v.7, p.153-160, 2007.

NELSON, L.R.; SCOTT, G.E. Diallel analysis of resistance of corn (Zea mays L.) to corn stunt . Crop Science, v.13, p.162-164, 1973.

OLIVEIRA, C.M. de; MOLINA, R.M.S.; ALBRES, R.S.; LOPES, J.R.S. Disseminação de molicutes do milho a longas distâncias por Dalbulus maidis (Hemiptera: Cicadellidae). Fitopatologia Brasileira, v.27, p.91-95, 2002a.

OLIVEIRA, E. de; CARVALHO, R.V.; DUARTE, A.P.; ANDRADE, R.A.; RESENDE, R.O.; OLIVEIRA, C.M. de; RECCO, P.C. Molicutes e vírus em milho na safrinha e na safra de verão. Revista Brasileira de Milho e Sorgo, v.1, p.38-46, 2002 b.

OLIVEIRA, E. de; OLIVEIRA, C.M. de; SOUZA, I.R.P.; MAGALHÃES, P.C.; CRUZ, I. Enfezamentos em milho: expressão de sintomas foliares, detecção dos molicutes e interações com genótipos. Revista Brasileira de Milho e Sorgo, v.1, p.53-62, 2002c.

OLIVEIRA, E. de; RESENDE, R.O.; GIMÉNESPECCI, M.L.P.; LAGUNA, I.G.; HERRERA, P.; CRUZ, I. Incidência de viroses e enfezamentos e estimativa de perdas causadas por molicutes em milho no Paraná. Pesquisa Agropecuária Brasileira, v.38, p.19-25, 2003.

OLIVEIRA, E.; DUARTE, A.P.; CARVALHO, R.V.; OLIVEIRA, A.C. Molicutes e vírus na cultura do milho no Brasil: caracterização e fatores que afetam sua incidência. In: OLIVEIRA, E. de; OLIVEIRA, C.M. de. (Ed.). Doenças em milho: molicutes, vírus, vetores, mancha por Phaeosphaeria. Sete Lagoas: Embrapa Milho e Sorgo; Brasília: Embrapa Informação Tecnológica, 2004. p.17-34.

OLIVEIRA, E. de; OLIVEIRA, C.M. de; MAGALHÃES, P.C.; ANDRADE, C.L.T.; HOGENHOUT, S.A. Spiroplasma and phytoplasma infection reduce kernel production, and nutrient and water contents of several but not all maize cultivars. Maydica, v.50, p.171-178, 2005.

PINHO, R.G. von. Metodologias de avaliação, quantificação de danos e controle genético da resistência do milho à Puccinia polysora e Physopella zeae. 1998. 147p. Tese (Doutorado) Universidade Federal de Lavras, Lavras.
SAS INSTITUTE. SAS onlinedoc: version 8. Cary: SAS Institute, 1999.

SCHUELTER, A.R.; SOUZA, I.R.P.; TAVARES, F.F.; SANTOS, M.X.; OLIVEIRA, E.; GUIMARÃES, C.T. Controle genético da resistência do milho à mancha por Phaeosphaeria. Revista Brasileira de Milho e Sorgo, v.2, p.80-86, 2003.

SCOTT, G.E.; ROSEKRANZ, E.E. Independent inheritance of corn stunt and maize dwarf mosaic in corn. Crop Science, v.14, p.104-106, 1974b.

SILVA, H.P.; BARBOSA, M.P.M.; NASS, L.L.; CAMARGO, L.E.A. Capacidade de combinação e heterose para resistência a Puccinia polysora Underw. em milho. Scientia Agricola, v.58, p.777-783, 2001.

SILVA, H.P.; MORO, J.R. Análise dialélica da resistência a Phaeosphaeria maydis em milho. Scientia Agricola, v.61, p.36-42, 2004.

SILVA, R.G. Fontes de resistência e controle genético dos enfezamentos do milho. 2002. 52p. Dissertação (Mestrado) Universidade Federal de Viçosa, Viçosa.

SILVA, R.G.; GALVÃO, J.C.C.; MIRANDA, G.V.; OLIVEIRA, E. de. Controle genético da resistência aos enfezamentos do milho. Pesquisa Agropecuária Brasileira, v.38, p.921-928, 2003.

SILVA, R.G.; GALVÃO, J.C.C.; MIRANDA, G.V.; OLIVEIRA, E. de. Identificação dos níveis e fontes de resistência aos enfezamentos do milho. Revista Brasileira de Milho e Sorgo, v.1, p.18-29, $2002 b$

SILVA, R.G.; GALVÃO, J.C.C.; MIRANDA, G.V.; SILVA, E. do C.; CORRÊA, L.A. Flutuação populacional de Dalbulus maidis (DeLong \& Wolcott, 1923) (Hemiptera: Cicadellidae) e avaliação de sintomas do complexo enfezamento em híbridos de milho. Revista Ciência e Agrotecnologia, v.26, p.292-300, 2002a.

SILVEIRA, F.T.; JUNQUEIRA, B.G.; SILVA, P.C.; MORO, J.R. Comportamento de linhagens elites de milho para resistência aos enfezamentos. Revista Brasileira de Milho e Sorgo, v.5, p.431-442, 2006.

Recebido em 4 de setembro de 2008 e aprovado em 10 de novembro de 2008 